\title{
Non-viral delivery of the connexin 43 gene with histone deacetylase inhibitor to human nasopharyngeal tumor cells enhances gene expression and inhibits in vivo tumor growth
}

\author{
YOSHIYUKI HATTORI, MASAYOSHI FUKUSHIMA and YOSHIE MAITANI \\ Institute of Medicinal Chemistry, Hoshi University, Shinagawa-ku, Tokyo 142-8501, Japan
}

Received February 1, 2007; Accepted March 19, 2007

\begin{abstract}
Dysregulation of connexin expression is believed to have a role in carcinogenesis, because levels of connexin are reduced in various tumors. We examined the role of connexin $43(\mathrm{Cx} 43)$ alone and combined with a histone deactylase (HDAC) inhibitor in tumor growth inhibition. The transfection of Cx43 plasmid DNA (pCMV-Cx43) into human nasopharyngeal cancer KB cells using folate-linked nanoparticles induced inhibition of cell growth. Cx43 induced a tumor suppressive effect via a gap junctional intercellular communication-independent mechanism. The transfection of pCMVCx43 along with an HDAC inhibitor, 4-phenylbutyrate (4-PB), enhanced $\mathrm{Cx} 43$ expression greatly in vitro, and inhibited significantly the tumor growth of $\mathrm{KB}$ cells and xenografts compared with that of pCMV-Cx43 alone. 4-PB induced increased expression of genes of DNA damage checkpoints and of apoptosis via the down-regulation of anti-apoptotic bcl-2 mRNA expression and up-regulation of the activity of the apoptosis-associated enzyme caspase-3/7. Thus, the amplified Cx43 expression by an antitumor agent, an HDAC inhibitor, may have great potential as a growth inhibitor for nasopharyngeal tumors.
\end{abstract}

\section{Introduction}

Deregulation of connexin $(\mathrm{Cx})$ expression is believed to play a part in carcinogenesis (1). Cx proteins have an essential role in gap junction intercellular communication (GJIC), which is often impaired among tumor cells and between tumor cells and surrounding normal cells. Connexin $43(\mathrm{Cx} 43)$ is a tumor-suppressor (2), and its expression is reduced in various tumors (3-10). Forced expression of the $\mathrm{Cx} 43$ gene in several Cx43-deficient tumor cell lines attenuated their malignant

Correspondence to: Dr Yoshiyuki Hattori, Institute of Medicinal Chemistry, Hoshi University, Shinagawa-ku, Tokyo 142-8501, Japan E-mail: yhattori@hoshi.ac.jp

Key words: connexin 43, histone deacetylase inhibitor, nasopharyngeal cancer, 4-phenylbutyrate, gene therapy, folate-linked nanoparticle, transfection, gap junction, apoptosis phenotype $(8,11)$. However, a truncated Cx43 not forming gap junctions, also inhibited tumor growth (12). Thus, the mechanisms by which the $\mathrm{Cx} 43$ gene inhibits tumor growth remain unclear. Regarding tumor gene therapy using the $\mathrm{Cx}$ gene, there are many reports about co-administration of the herpes simplex thymidine kinase (HSV-tk) gene (13) or a chemotherapeutic agent $(14,15)$. Enforced expression of Cx resulted in a dramatic suppression of tumor growth when $\mathrm{Cx}$ gene-transfected tumor cells were implanted into mice (1). However, the application of $\mathrm{Cx}$ gene delivery in vivo by direct injection into tumor-bearing mice with a vector has not been reported except for injection of the $\mathrm{Cx} 26$ gene with an adenoviral vector (16). One major obstacle to applications in vivo is poor transgene expression, therefore, a transfer system including an efficient vector for the $\mathrm{Cx}$ gene is required to strongly induce gene expression in vivo.

Histone deacetylase (HDAC) inhibitors such as sodium butyrate (SB), 4-phenylbutyrate (4-PB) and trichostatin A (TSA) cause cell-cycle arrest in the $\mathrm{G}_{1}$ and/or $\mathrm{G}_{2}$ phase and induce differentiation and/or apoptosis in a variety of cell types (17). Inhibition of HDAC activity induces the transcriptional activation of certain genes, such as that for the cyclin-dependent kinase inhibitor p21, which are thought to suppress tumor growth and prevent cell cycle progression $(18,19)$. Several HDAC inhibitors inhibit tumor growth in animal models with little toxicity in non-tumor cells (20). Therefore, HDAC inhibitors are a new class of antitumor agent being evaluated in clinical trials. HDAC inhibitors also possess the capacity to enhance the expression of a wide variety of transiently transfected transgenes in tumors both in vitro and in vivo through their effect on the acetylation of histones $(19,21)$. Combining of p53 gene therapy with an HDAC inhibitor, FR901228 or $\mathrm{SB}$, enhanced therapeutic efficacy in vitro (22) and in vivo (23). The introduction of both the HSV-tk gene and FR901228 into melanoma xenografts enhanced the antitumor effect (24). However, the effect of transfection of the $\mathrm{Cx}$ gene combined with an HDAC inhibitor has not been reported.

The development of non-viral and tumor-selective delivery vectors for gene transfer in vivo is necessary for the clinical application of therapeutic genes. Folate receptor (FR) has been found to be overexpressed in a wide range of tumors (25). We previously reported that folate-linked nanoparticles (NP-F) could efficiently deliver DNA into human nasopharyngeal cancer KB cells, which overexpressed FR $(26,27)$. 
Therefore, we used NP-F as a DNA transfection vector for cancer gene therapy.

In the present study, we investigated whether the transfection of plasmid DNA (pCMV-Cx43) coding for the Cx43 gene by NP-F combined with an HDAC inhibitor induced inhibition of $\mathrm{KB}$ cell growth. A novel combination of pCMV$\mathrm{Cx} 43$ and an HDAC inhibitor, 4-PB enhanced the expression of $\mathrm{Cx} 43$ protein and induced significantly greater growth inhibition in KB cells and the tumor xenografts compared with pCMV-Cx43 alone. This combination increased apoptosis via down-regulation of bcl-2 mRNA expression and upregulation of caspase-3/7 activity.

\section{Materials and methods}

Materials. SB and 4-PB were purchased from Wako Pure Chemicals (Osaka, Japan). TSA was supplied by Sigma Chemical Co. (St. Louis, MO, USA). 1,1'-Dioctadecyl-3, 3, 3', 3'-tetramethylindocarbocyamine perchlorate (DiI) was obtained from Lambda Probes \& Diagnostics (Graz, Austria). Calcein-AM was purchased from Dojindo (Kumamoto, Japan). The Pica gene luciferase assay kit was obtained from Toyo Ink Mfg. Co. Ltd. (Tokyo, Japan). Bicinchonic acid (BCA) protein assay reagent was purchased from Pierce (Rockford, IL, USA). All reagents were of analytical grade. All other chemicals used were of reagent grade. Folate-deficient RPMI-1640 medium and fetal bovine serum were purchased from Life Technologies, Inc. (Grand Island, NY, USA).

Preparation of plasmid DNA. In the construction of the plasmid pCMV-Cx43 encoding the Cx43 gene under the control of the CMV promoter, the Cx43 and CMV promoter DNAs were amplified as described previously (28). After the Cx43 DNA amplification, this DNA was subcloned into an NcoI/ XbaI-digested pGL3-control (Promega, Madison, WI, USA). Subsequently, the amplified CMV promoter DNA was subcloned into the HindIII and KpnI restriction sites of the above plasmid.

In the construction of the plasmid pCMV-Cx43-EGFP, EGFP was fused in frame to the carboxyl terminus of $\mathrm{Cx} 43$. The DNA coding for EGFP was amplified by PCR using pEGFP-C1 (Clontech, CA, USA) as a template and the following EGFP-specific primers: EGFP forward primer (5'-TT GGCGCCGTGGGCAAGGGCGAGGAGCTG-3'), EGFP reverse primer (5'-TTTCTAGATTAGGACTTGTACAGCT CCTCC-3'). The forward primer contained a NarI restriction site (underlined). The reverse primer contained an $\mathrm{XbaI}$ restriction site (underlined). The cDNA encoding bp 1-1146 of human $\mathrm{Cx} 43$ was amplified by PCR using the following Cx43-specific primers: Cx43 forward primer (5'-GCAAG CTTaccATGGGTGACTGGAGCGCCT-3'), Cx43 reverse primer (5'-ATGGCGCCGATCTCCAGGTCATCAGGCC-3'). The forward primer contained a 3-bp optimal Kozak sequence (in lower case letters) together with a HindIII restriction site (underlined). The reverse primer coded for bp 1129-1146 of Cx43 with a NarI restriction site (underlined). After the DNA amplification of EGFP, this DNA was digested with NarI and $X b a \mathrm{I}$ and was ligated into a NarI and XbaI-digested pGL3-enhancer (Promega). Subsequently, the amplified PCR fragment of $\mathrm{Cx} 43$ was cloned into the HindIII and NarI- restriction sites of the above plasmid, and then the CMV promoter DNA was subcloned into the HindIII and KpnIrestriction sites as described above.

In the construction of the plasmid pCMV-luc encoding the luciferase gene under the control of the CMV promoter, the CMV promoter DNA was subcloned into the HindIII and $K p n I$ restriction sites of pGL3-enhancer. pGL3-basic encoding the luciferase gene without promoter was obtained from Promega and used as a control plasmid. A protein-free preparation of these plasmids was purified following alkaline lysis using maxiprep columns (Qiagen, Hilden, Germany).

Preparation of folate-linked nanoparticles. Cholesteryl-3ßcarboxyamidoethylene-N-hydroxyethylamine (OH-Chol) was synthesized as previously reported (27). NP-F as a gene transfection reagent was prepared with lipids [OH-Chol: Tween-80 (NOF Co. Ltd., Tokyo, Japan): folate-polyethylene glycol-distearoylphosphatidylethanolamine (mean molecular weight of PEG: 2,000 kDa) = 94:5:1, molar ratio = 10:1.3:0.65 weight] in $10 \mathrm{ml}$ of water using a modified ethanol injection method as described previously (27).

Cell culture. KB cells were from the Cell Resource Center for Biomedical Research, Tohoku University (Miyagi, Japan). Prostate cancer LNCaP cells were supplied by the Department of Urology, Keio University Hospital (Tokyo, Japan). All the cell lines used in this study were grown in a folate-deficient RPMI-1640 medium supplemented with $10 \%$ heat-inactivated fetal bovine serum and kanamycin $(100 \mu \mathrm{g} / \mathrm{ml})$ at $37^{\circ} \mathrm{C}$ in a $5 \% \mathrm{CO}_{2}$ humidified atmosphere.

In vitro transfection. Cell cultures were prepared by plating cells in a $35-\mathrm{mm}$ culture dish $24 \mathrm{~h}$ prior to each experiment. Based on preliminary experiments in vitro, the optimized charge ratio (+/-) of cationic lipid to DNA was determined as 3:1 (27). The NP-F and plasmid DNA complex (NP-F nanoplex) at a charge ratio (+/-) of cationic lipid to DNA of $3 / 1$ was formed by addition of NP to $2 \mu \mathrm{g}$ of plasmid DNA in $50 \mathrm{mM} \mathrm{NaCl}$ with gentle shaking and left at room temperature for $10 \mathrm{~min}$. The NP-F nanoplex was diluted in $1 \mathrm{ml}$ of medium supplemented with $10 \%$ serum and then incubated with cells for $24 \mathrm{~h}$. For the co-introduction of the HDAC inhibitor, the NP-F nanoplex was diluted in the medium containing the HDAC inhibitor to the concentration indicated in the figure legends.

In vitro cell growth. $\mathrm{KB}$ cells were seeded separately at a density of $1 \times 10^{4}$ cells per well in 96-well plates and maintained for $24 \mathrm{~h}$ before transfection in RPMI medium supplemented with $10 \%$ serum. The cells at $30 \%$ confluence in the well were transfected with the NP-F nanoplexes using $0.2 \mu \mathrm{g}$ of pCMV-Cx43 or pGL3-basic in the presence or absence of the HDAC inhibitor and incubated for $48 \mathrm{~h}$. The cell number was determined with a WST-8 assay (Dojindo Laboratories).

Immunoblotting. $\mathrm{KB}$ cells were seeded in a $35-\mathrm{mm}$ culture dish and incubated overnight. The cells at $30 \%$ confluency were transfected with pCMV-Cx43 or pGL3-basic in the presence or absence of the HDAC inhibitor and then incubated for $24 \mathrm{~h}$. The cells were suspended in lysis buffer [1\% 
Triton X-100 in phosphate-buffered saline pH 7.4 (PBS)], and then centrifuged at 15,000 rpm for $10 \mathrm{~min}$. The supernatants $(10 \mu \mathrm{g}$ protein) were resolved on a $12 \%$ sodium dodecyl sulphate-polyacrylamide gel by electrophoresis (SDS-PAGE) and transferred to a polyvinylidene difluoride (PVDF) membrane (FluoroTrans ${ }^{\circledR}$ W, PALL Gelman Laboratory, Ann Arbor, MI, USA). Expression of the Cx43 protein was identified using a specific rabbit antiserum (Sigma) and acetylated histone $\mathrm{H} 3$ was detected by rabbit anti-human acetyl histone H3 antibody (Sigma). The goat anti-rabbit IgG peroxidase conjugate (Santa Cruz Biotechnology, Inc., Santa Cruz, CA, USA) was used as secondary antibody. These proteins were detected with peroxidase-induced chemiluminescence (Super Signal West Pico Chemiluminescent Substrate, Pierce).

RNA isolation and RT-PCR. KB cells were seeded in a $35-\mathrm{mm}$ culture dish and incubated overnight. The cells at $30 \%$ confluency were transfected with pCMV-Cx43 or pGL3basic in the presence or absence of $1 \mu \mathrm{M}$ TSA, $1 \mathrm{mM}$ SB or $1 \mathrm{mM} 4-\mathrm{PB}$, and then incubated for $24 \mathrm{~h}$. Total RNA was isolated from the cells using NucleoSpin RNA II (MachereyNagel, Germany). First-strand cDNA was synthesized from $5 \mu \mathrm{g}$ of total RNA as previously described (28). For RT-PCR, the $25-\mu 1$ reaction volume contained the following: $1 \mu 1$ of synthesized cDNA, 10 pmol of each specific primer pair, and 0.25 units of Ex Taq DNA polymerase (Takara Shuzo Co., Ltd) with a PCR buffer containing $1.5 \mathrm{mM} \mathrm{MgCl}_{2}$ and $0.2 \mathrm{mM}$ of each dNTP. The profile of PCR amplification consisted of denaturation at $94^{\circ} \mathrm{C}$ for $0.5 \mathrm{~min}$, primer annealing at $58^{\circ} \mathrm{C}$ for $0.5 \mathrm{~min}$, and elongation at $72^{\circ} \mathrm{C}$ for $1 \mathrm{~min}$ for 25 cycles. For the amplification of human $\mathrm{Cx} 43$, the primers Cx43-FW, 5'-CTC ATGTGTTCTATGTGATG-3', and Cx43-RW, 5'-ATTGCG GCAAGAAGAATTGT-3', were used. For the amplification of human bcl-2, the primers bcl-2-FW, 5'-TGGAGAGCGTC AACCGGGAG-3', and bcl-2-RW, 5'-CCGTACAGTTCCAC AAAGGC-3', were used. For the amplification of the housekeeping gene $\beta$-actin, the primers $\beta$-actin-FW, 5'-ACCCACA CTGTGCCCATCTA-3', and ß-actin-RW, 5'-CTGCTTGCT GATCCACATCT-3', were used. PCRs of Cx43, bcl-2 and $\beta$-actin were performed at the same cycle run for all samples. The PCR products for $\mathrm{Cx} 43$, bcl- 2 and $\mathrm{B}$-actin were analyzed by $1.5 \%$ agarose gel electrophoresis in a Tris-borate-EDTA (TBE) buffer. The products were visualized by ethidium bromide staining.

Real-time PCR was performed on the corresponding cDNA synthesized from each sample described above. The optimized settings were transferred to the real-time PCR protocol with the iCycler MyiQ detection system (Bio-Rad Laboratories, Hercules, CA, USA) and SYBR-Green I assay (iQ $^{\text {TM }}$ SYBR-Green Supermix, Bio-Rad Laboratories) was used for quantification. Samples were run in triplicate and the expression levels of $\mathrm{Cx} 43$ and bcl-2 mRNA were normalized to the amount of $\beta$-actin in the same sample.

cDNA array. KB cells were seeded in a $35-\mathrm{mm}$ culture dish and incubated overnight. The cells at $30 \%$ confluency were transfected with pGL3-basic or pCMV-Cx43 in the presence or absence of $1 \mu \mathrm{M}$ TSA or $1 \mathrm{mM} 4-\mathrm{PB}$. After $24 \mathrm{~h}$ of incubation, total RNA was isolated from the cells as described above. A non-radioactive human cell cycle gene array (GEArray Q series human cell cycle gene assay, Super Array Inc., MD, USA) was used to analyze the gene expression profile of the cell cycle, DNA damage checkpoint and ATM pathway. Briefly, $5 \mu \mathrm{g}$ of total RNA was used as a template to produce biotinylated cDNA probes. RNA was reversetranscribed using gene-specific primers with biotin-16-dUTP. Biotinylated cDNA probes were denatured and hybridized to cell cycle gene-specific cDNA fragments spotted on membranes. The GEArray membranes were then washed and blocked with GEA blocking solution, and incubated with alkaline phosphatase-conjugated streptavidin. The hybridized biotinylated probes on the membrane were detected by a chemiluminescent method using the alkaline phosphatase substrate, CDP-Star. The membranes were exposed to chemiluminescence film (Hyperfilm ${ }^{\mathrm{TM}} \mathrm{ECL}^{\mathrm{TM}}$, Amersham Bioscience Corp., Piscataway, NJ, USA) for $10 \mathrm{sec}$. The results were analyzed using free ScanAlyze software (developed by Dr Michael Eisen), which converts a grayscale TIFF image of spots into numerical data (median pixel intensity), and then the gene expression profiles were compared using GEArray analyzer software (Super Array, Inc.). Each array comprised 96 marker genes in quadruplicate, 4 positive controls including $\beta$-actin, glyceraldehyde-3-phosphate dehydrogenase (GAPDH), cyclophilin A (PPIA) and ribosomal protein L13a, and a negative control, the bacterial plasmid pUC18. Intensity was calculated from each array by subtracting the negative control from each spot and normalized against the housekeeping gene PPIA. Gene expression ratios from each experiment were calculated by using the average normalized intensities from each array.

Cell cycle analysis. KB cells were seeded in a 35-mm culture dish and incubated overnight. The cells at $30 \%$ confluency were transfected with pCMV-Cx43 or pGL3-basic in the presence or absence of $1 \mu \mathrm{M}$ TSA, $1 \mathrm{mM} \mathrm{SB}$ or $1 \mathrm{mM} 4-\mathrm{PB}$ in medium. After $24 \mathrm{~h}$ of incubation, the cells were harvested with EDTA after a wash with ice-cold PBS. Detached cells were washed once with ice-cold PBS and gently suspended in PBS-EtOH $(70 \%)$ and fixed overnight at $4^{\circ} \mathrm{C}$. For staining, the fixed cells were washed once in PBS and then resuspended in PBS with $50 \mu \mathrm{g} / \mathrm{ml}$ propidium iodide (PI) and $0.5 \%$ RNase A. After $30 \mathrm{~min}$ at $37^{\circ} \mathrm{C}$, the cells were processed for FACS analysis of the PI-fluorescence by a FACSCalibur flow cytometer (Becton-Dickinson, San Jose, CA) equipped with a 488-nm argon ion laser. Data for 10,000 fluorescent events were obtained by recording forward scatter (FSC), side scatter (SSC), and PI-fluorescence (585/42 nm).

Assesment of gap junctional intercellular communication. The FACS analysis of the GJIC reported by Robe et al (29) was modified. Briefly, cells grown in $35-\mathrm{mm}$ dishes were labeled for 1-h incubation with either $5 \mu \mathrm{M}$ calcein-AM or $5 \mu \mathrm{M}$ DiI in the medium. The two labeled cells were mixed in equal proportions in 35-mm dishes and incubated for $24 \mathrm{~h}$. Subsequently, pCMV-Cx43 or pGL3-basic was transfected with NP-F into the mixed cells in the presence or absence of $1 \mathrm{mM} \mathrm{SB}, 1 \mathrm{mM} 4-\mathrm{PB}$ or $1 \mu \mathrm{M}$ TSA. After $24 \mathrm{~h}$ of incubation, the cells were trypsinized, washed in PBS and processed for a FACS analysis of the calcein-AM- and 
DiI-fluorescences with a FACSCalibur flow cytometer as described above. Data for 10,000 fluorescent events were obtained by recording calcein-AM-fluorescence $(530 / 30 \mathrm{~nm})$ and DiI-fluorescence (585/42 $\mathrm{nm})$.

Confocal microscopy. $\mathrm{KB}$ and $\mathrm{LNCaP}$ cells, respectively, were plated into $35-\mathrm{mm}$ culture dishes. The cells at $30 \%$ confluency were transfected with pCMV-Cx43-EGFP in the presence or absence of $1 \mu \mathrm{M}$ TSA or $1 \mathrm{mM} 4-\mathrm{PB}$ by incubation for $24 \mathrm{~h}$. Examinations were performed with a Radiance 2100 confocal laser scanning microscope (Bio-Rad Laboratories) as previously described (28). Cx43-EGFP was imaged using the 488-nm excitation line of an argon laser, and fluorescence emission was observed with a filter, HQ515/30.

Luciferase and caspase-3/7 activities. KB cells were seeded in a $35-\mathrm{mm}$ culture dish and incubated overnight. The cells at $30 \%$ confluency were transfected with pGL3-basic or pCMV-Cx43 in the presence or absence of $1 \mu \mathrm{M}$ TSA, $1 \mathrm{mM}$ $\mathrm{SB}$ or $1 \mathrm{mM} 4-\mathrm{PB}$ by incubation for $24 \mathrm{~h}$. For measuring caspase-3/7 activity, a homogenous assay (Caspase-Glo ${ }^{\text {TM }}$ 3/7 assay, Promega, Madison, WI, USA) was performed as described in the assay instructions. Luciferase activity was measured using the luciferase assay system (Pica Gene, Toyo Ink Mfg. Co. Ltd., Tokyo, Japan) as previously reported (30).

Gene expression in vivo. To generate $\mathrm{KB}$ tumor xenografts, $1 \times 10^{7}$ cells suspended in $50 \mu 1$ of RPMI medium were inoculated subcutaneously into the flanks of male BALB/c nu/nu mice (7 weeks of age, Clea Japan, Inc., Tokyo, Japan). The tumor volume was calculated using the formula: tumor volume $=0.5 \mathrm{x} \mathrm{a} \mathrm{x} \mathrm{b}^{2}$, where $\mathrm{a}$ and $\mathrm{b}$ are the larger and smaller diameters, respectively. Based on a preliminary experiment of gene expression induced by intratumoral injection, the optimized ratio of cationic lipid to DNA was determined as 1.5:1. For detection of luciferase gene expression in tumor, the nanoplex was formed by addition of NP-F (23.8 $\mu 1)$ to $10 \mu \mathrm{g}$ of pCMV-luc with gentle shaking and standing at room temperature for $10 \mathrm{~min}$. When the average volume of KB xenograft tumors reached approximately $600 \mathrm{~mm}^{3}$, the NP-F nanoplexes of $10 \mu \mathrm{g}$ of plasmid per tumor were directly injected into xenografts. Twenty-four hours after injections, the mice were injected with D-luciferin (potassium salt, Wako Pure Chemicals, Osaka, Japan) dissolved in PBS (125 mg/kg of body weight) into the peritoneal cavity and subsequently anesthetized by i.m. injection of $50 \mathrm{mg} / \mathrm{kg}$ body weight of pentobarbital (Nembutal, Dainippon Pharmaceutical Co., Ltd., Osaka, Japan). In vivo bioluminescence imaging was performed by using a NightOWL LB981 NC100 system (Berthold Technologies, Bad Wildbad, Germany). A gray scale bodysurface reference image was collected using the NightOWL LB981 CCD camera. Photons emitted from luciferase within the mice were collected and integrated for a 2-min period. A pseudocolor luminescent image from blue (least intense) to red (most intense), representing the spatial distribution of the detected photons emitted within the mice, was generated using WinLight software (Berthold Technologies). The overlay of the real image and the luminescence representation allowed the localization and measurement of luminescence emitted from the tumor xenografts.
For detection of EGFP expression in tumor, the NP-F nanoplexes of $10 \mu \mathrm{g}$ of $\mathrm{pEGFP}-\mathrm{C} 1$ plasmid per tumor were directly injected into KB xenografts. Twenty-four hours after injections, tumors were removed for preparation of cryosections. The excised tumors were immediately frozen, sectioned at $20 \mu \mathrm{m}$ thick and mounted. The expression of EGFP protein was observed using fluorescence microscopy.

Assessment of KB tumor growth. When the average volume of $\mathrm{KB}$ xenograft tumors reached $150 \mathrm{~mm}^{3}$ (day 0), these mice were divided into four groups: group I, pGL3-basic $(10 \mu \mathrm{g})$ as a control; group II, pCMV-Cx43 $(10 \mu \mathrm{g})$; group III, pGL3basic $(10 \mu \mathrm{g})$ plus $1 \mathrm{mg} 4-\mathrm{PB}$; and group IV, pCMV-Cx43 $(10 \mu \mathrm{g})$ plus $1 \mathrm{mg} 4-\mathrm{PB}$. Each experimental group consisted of 4 tumors. The NP-F nanoplexes at a charge ratio (+/-) of $1.5 / 1$ of cationic lipid to DNA were formed as described in the above section. The nanoplexes of $10 \mu \mathrm{g}$ of plasmid per tumor were directly injected into xenografts on days 0,2 and 4. At $10 \mathrm{~min}$ after each DNA transfection, $20 \mu \mathrm{l}$ of $50 \mathrm{mg} / \mathrm{ml}$ 4-PB dissolved in DMSO was directly injected into the xenografts. The tumor volume was measured at days $0,2,4$, $6,8,11$ and 13. At day 13, all mice were sacrificed, and the tumor weights were measured. Tumor volume and weight are shown as the mean $\pm \mathrm{SE}$ and $\pm \mathrm{SD}$, respectively. The excised tumors were immediately frozen, sectioned $20-\mu$ m thick and mounted. The sections were stained with hematoxylin and pure eosin (Muto Pure Chemicals Co., Ltd., Tokyo, Japan) for histopathological examination.

Statistical analysis. The statistical significance of differences between mean values was determined using Welch's t-test. Multiple comparisons were performed with an analysis of variance followed by the Bonferroni/Dunn test. P-values $<0.05$ were considered significant.

\section{Results}

Amplification of CX43 gene expression by HDAC inhibitors. In this study, we used NP-F for in vitro and in vivo DNA transfection into $\mathrm{KB}$ tumor. The in vitro transfection efficiency of pEGFP-C1 into KB cells by NP-F was $\sim 20-30 \%$ at $30 \%$ confluency by flow cytometric analysis (data not shown). Commercially available transfection reagent Lipofectamine 2000 (Invitrogen Corp., Carlsbad, CA, USA) exhibited 40-50\% transfection efficiency of the cells at $30 \%$ confluency, however, Lipofectamine 2000 is known to be cytotoxic and to induce expression of many apoptotic genes. In fact, the Lipofectamine 2000 significantly decreased cell viability after transfection into KB cells. Therefore, we decided to use NP-F for DNA transfection into $\mathrm{KB}$ cells.

To investigate whether the transfection of pCMV-Cx43 induced growth inhibition in the cells, we initially examined cell growth after transfection using a colorimetric viability assay. In this study, we used pGL3-basic as a control plasmid. Forty-eight hours after transfection, pCMV-Cx43 had a significant suppressive effect in KB cells (Fig. 1A).

Next, to induce the complete growth suppression of KB cells, we investigated whether the transfection of pCMVCx43 with an HDAC inhibitor, TSA, SB or 4-PB, enhanced the expression of $\mathrm{Cx} 43$. In a preliminary study, we observed 


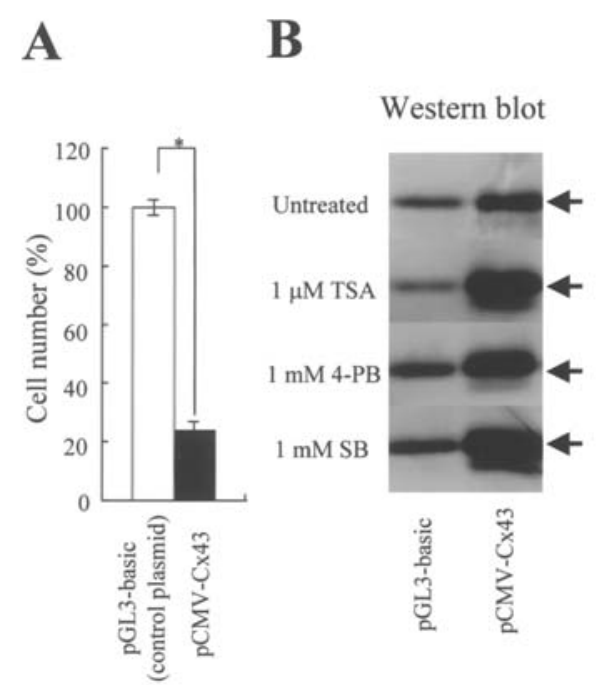

C

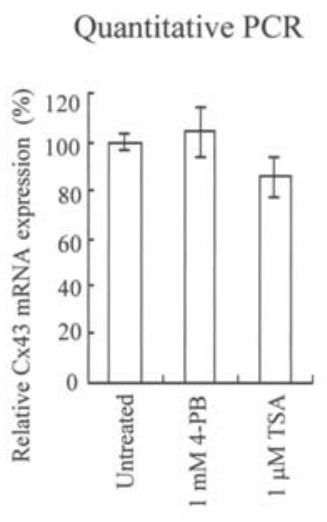

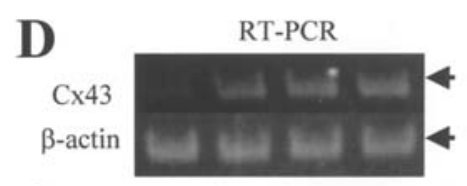

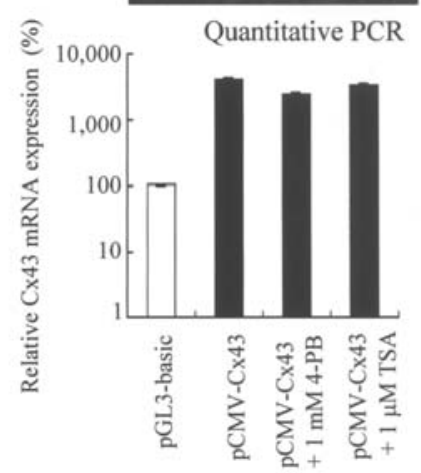

Figure 1. Effect on cell growth of expression of Cx43 (A). pGL3-basic was used as a control plasmid. The cells at 30\% confluency were transfected with pCMV-Cx43 or pGL3-basic. Cell number was measured $48 \mathrm{~h}$ after transfection. Statistical significance of the data was evaluated with the Welch's t-test. ${ }^{*} \mathrm{P}<0.05$, compared with pGL3-basic. Effect of HDAC inhibitors on the expression of Cx43 protein (B) and mRNA (C and D) in KB cells. The cells transfected with pCMV-Cx43 or pGL3-basic were exposed to $1 \mu \mathrm{M}$ TSA, $1 \mathrm{mM} 4-\mathrm{PB}$ or $1 \mathrm{mM}$ SB for $24 \mathrm{~h}$ (B and D). The cells were exposed to $1 \mu \mathrm{M}$ TSA or $1 \mathrm{mM}$ 4-PB for $24 \mathrm{~h}(\mathrm{C})$. Western blot (B) and quantitative PCR (C and D) and RT-PCR (D) analyses were performed $24 \mathrm{~h}$ after transfection. (B and C) The 3 -actin housekeeping gene was used as the control. The relative amount of Cx43 mRNA in the cells was compared with a SYBR-Green I-based quantitative PCR analysis. The y-axis indicates Cx43 mRNA expression (\%) of untreated (C) or pGL3-basic-transfected cells (D). The expression level of Cx43 mRNA was normalized to the amount of $\beta$-actin in the same sample. Each result represents the mean $\pm \operatorname{SD}(n=3)$.
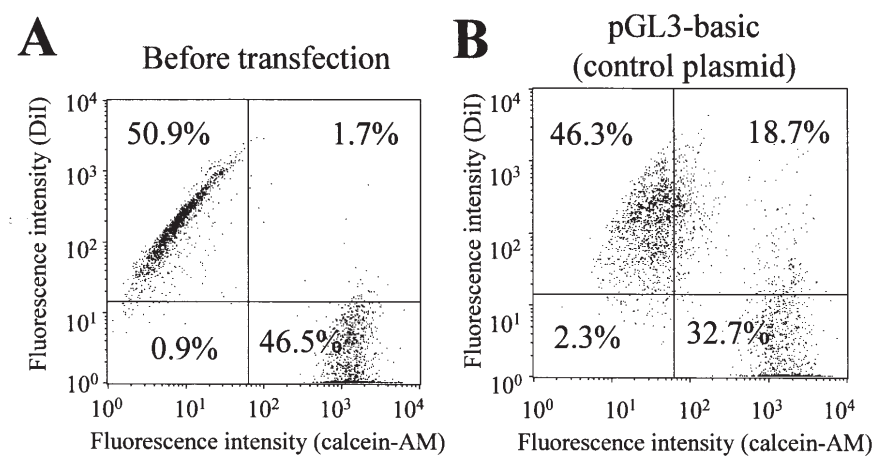

C pCMV-Cx43
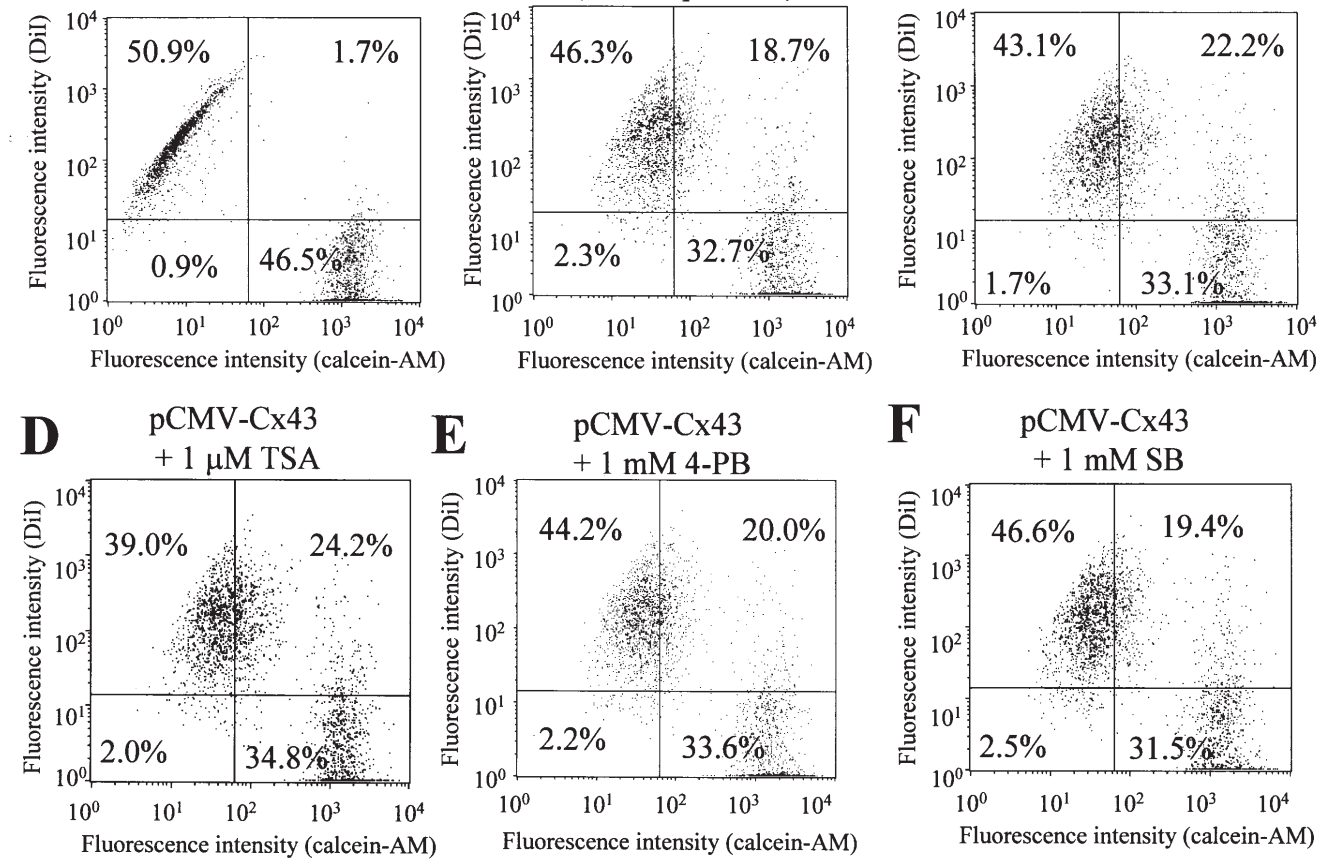

Figure 2. Gap junction-mediated transfer of fluorescent dyes in the presence and absence of HDAC inhibitors by FACS analysis. KB cells were pre-loaded with DiI and calcein-AM fluorescent probes. While DiI was retained in the preloaded cells, calcein-AM spread to DiI-positive cells, indicating gap junctionmediated transfer. The cells preloaded with DiI and calcein-AM were mixed in equal proportions, plated, and incubated for $24 \mathrm{~h}$. The cells were transfected with pCMV-Cx43 or pGL3-basic in the presence or absence of $1 \mu \mathrm{M}$ TSA, $1 \mathrm{mM}$ SB or $1 \mathrm{mM} 4$-PB and incubated for another $24 \mathrm{~h}$. Upper left quadrant, calcein-AM-loaded cells; lower right quadrant, DiI-tagged cells; upper right quadrant, DiI-tagged cells that have incorporated calcein-AM. Histogram of DiItagged and calcein-AM-loaded cells before co-incubation (A); pGL3-basic-transfected cells (B); pCMV-Cx43-transfected cells (C); pCMV-Cx43 plus TSAtransfected cells (D); pCMV-Cx43 plus 4-PB-transfected cells (E); pCMV-Cx43 plus SB-transfected cells (F).

the highest levels of $\mathrm{Cx} 43$ protein when the cells were co-introduced with $1 \mu \mathrm{M}$ TSA, $1 \mathrm{mM} \mathrm{SB}$ and $1 \mathrm{mM} 4-\mathrm{PB}$, respectively (data not shown). Therefore, in the subsequent experiment, we used these concentrations as optimal. The expression of endogenous $\mathrm{Cx} 43$ protein was detected moderately in KB cells (Fig. 1B, untreated cells transfected with 

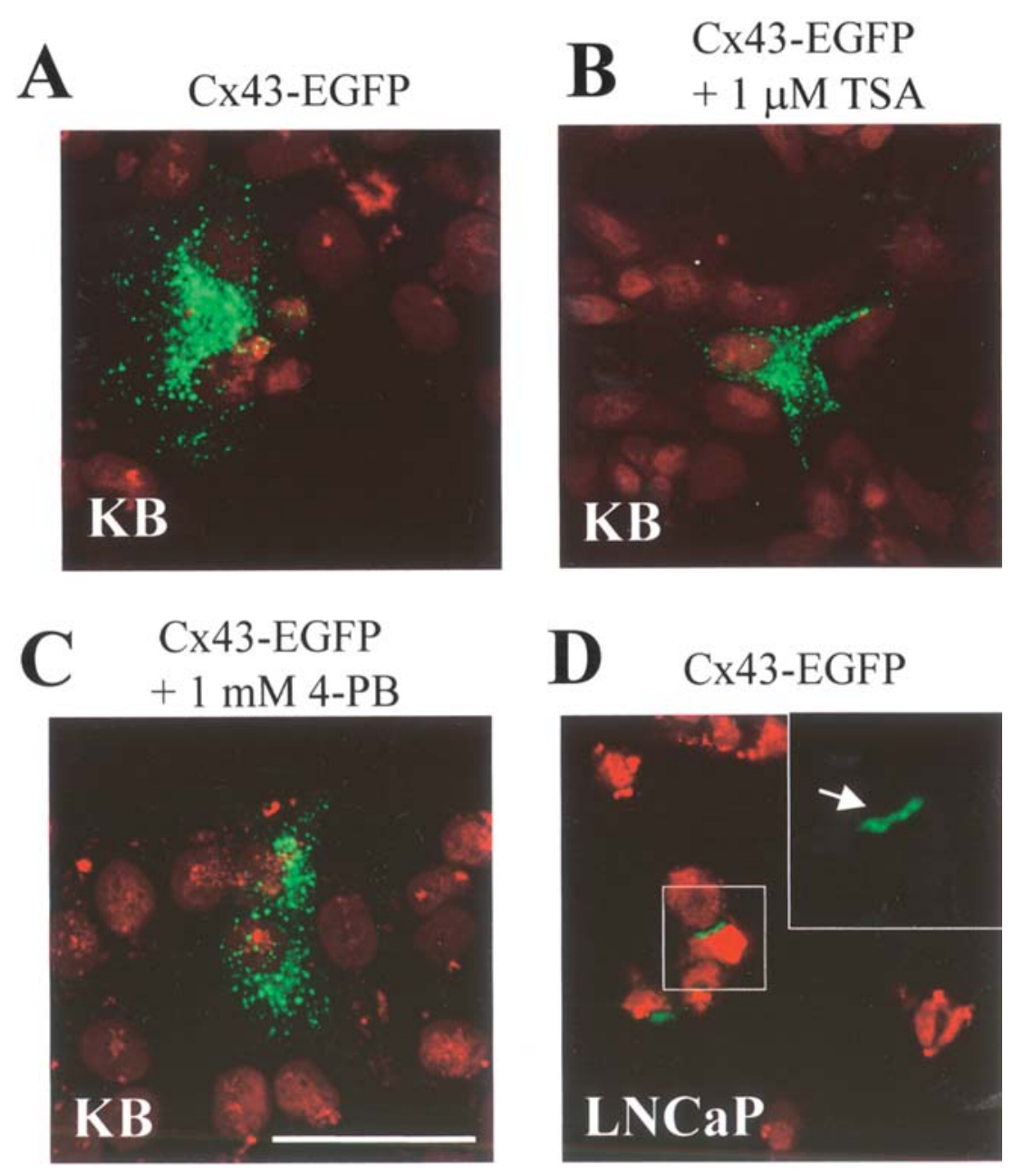

Figure 3. Localization of Cx43-EGFP in KB (A-C) and LNCaP cells (D). KB cells were transfected with pCMV-Cx43-EGFP in the absence (A) or presence of $1 \mu \mathrm{M}$ TSA (B) or $1 \mathrm{mM} 4-\mathrm{PB}$ (C) for $24 \mathrm{~h}$. LNCaP cells were transfected with pCMV-Cx43-EGFP for $24 \mathrm{~h}$ (D). The Cx43-EGFP was visualized by confocal microscopy (magnification $\mathrm{x} 1,200$ ). The red signals show the location of the nucleus, and the green signals, that of the Cx43-EGFP. Scale bar, $50 \mu \mathrm{m}$. Confocal images revealed that Cx43-EGFP was transported inefficiently to the cell surface and assembled into gap junctions in KB cells (A-C) while Cx43 was assembled more efficiently into gap junctions in LNCaP cells (D). Arrowheads indicate the junctional plaque.

pGL3-basic), and was weakly increased when the cells were treated with 4-PB or SB, but not TSA (Fig. 1B, pGL3-basic). When the cells were co-transfected with pCMV-Cx43 plus an HDAC inhibitor, the exogenous expression of $\mathrm{Cx} 43$ protein was strongly increased in the cells treated with each inhibitor, compared with those not treated with an inhibitor (Fig. 1B, pCMV-Cx43). Furthermore, we confirmed the increased expression of exogenous protein by HDAC inhibitors using pCMV-luc in the cells; the luciferase activity increased $\sim 2$ - and 6-fold on treatment with TSA, and 4-PB and SB, respectively (data not shown). To confirm the effect on acetylation in histone by HDAC inhibitors, we analyzed the intracellular level of histone $\mathrm{H} 3$ acetylation using a specific antibody against acetylated histone $\mathrm{H} 3$. When $\mathrm{KB}$ cells were co-transfected with pCMV-Cx43 and TSA, SB or 4-PB, the increased Cx43 expression correlated with the increased acetylation of histone H3 (data not shown). The acetylation levels of histone H3 by HDAC inhibitors corresponded with a previous report (31).

To analyze the effect of HDAC inhibitors on the transcription of Cx43 mRNA, RT-PCR and quantitative PCR analyses were carried out in the cells transfected with pCMV$\mathrm{Cx} 43$ in the presence or absence of HDAC inhibitors. As shown in Fig. 1C, endogenous Cx43 mRNA did not increase on treatment with 4-PB or TSA. In the cells transfected with pCMV-Cx43, the expression of Cx43 mRNA was 40 -fold higher than that with pGL3-basic (Fig. 1D). However, in the cells co-transfected with TSA or 4-PB, no amplification of Cx43 mRNA was observed compared to the cells without an HDAC inhibitor (Fig. 1D). Thus the amplified expression of Cx43 protein might result from an increase in $\mathrm{Cx} 43$ gene translation and/or from an indirect effect on stabilization of Cx43 protein by HDAC inhibitors.

Defective GJIC in KB tumor cells. To investigate whether the amplified expression of $\mathrm{Cx} 43$ protein by pCMV-Cx43 plus the HDAC inhibitor caused gap junctions to form, we assessed the transfer of calcein-AM, a cytoplasmic dye that crosses gap junctions, in a co-culture of calcein-AM-loaded cells and cells marked with DiI, a non-diffusible membrane fluorescent dye, by FACS analysis. pGL3-basic-transfected cells showed slight GJIC-mediated transfer of calcein-AM (18.7\%) after 48-h culture (Fig. 2B), indicating that other kinds of $\mathrm{Cx}$ endogenously expressed in $\mathrm{KB}$ cells induced GJIC. The pCMV-Cx43-transfected cells did not exhibit a great increase 
Table I. Differential expression of genes related to the cell cycle in KB cells on transfection of pCMV-Cx43 and/or treatment with HDAC inhibitors.

\begin{tabular}{|c|c|c|c|c|}
\hline Gene name & $\begin{array}{l}\text { pGL3-basic- } \\
\text { transfected cells }\end{array}$ & $\begin{array}{l}\text { pCMV-Cx43- } \\
\text { transfected cells }\end{array}$ & $\begin{array}{c}\mathrm{pCMV}-\mathrm{Cx} 43- \\
\text { transfected cells }+1 \mathrm{mM} 4-\mathrm{PB}\end{array}$ & $\begin{array}{c}\mathrm{pCMV}-\mathrm{Cx} 43- \\
\text { transfected cells }+1 \mu \mathrm{M} \text { TSA }\end{array}$ \\
\hline \multicolumn{5}{|l|}{$\overline{\mathrm{G}_{1}}$} \\
\hline CDC7 & 17.1 & $58.2(3.4)$ & $77.0(4.5)$ & $81.2(4.7)$ \\
\hline cdk2 & N.D & 18.3 & 13.5 & 9.1 \\
\hline p16 & 12.3 & $79.1(6.5)$ & $70.6(5.8)$ & $41.7(3.4)$ \\
\hline Cks1p9 & 42.6 & $84.1(2.0)$ & $74.6(1.8)$ & $26.3(0.6)$ \\
\hline Cullin2 & N.D & 60.9 & 66.2 & 48.8 \\
\hline Cullin3 & N.D & 22.2 & 10.2 & 30.1 \\
\hline Cullin4B & N.D & 19.7 & 26.3 & 10.5 \\
\hline E2F-4 & 45.0 & $89.2(2.0)$ & $86.8(1.9)$ & $78.0(1.7)$ \\
\hline Nedd8 & 13.8 & $42.3(3.1)$ & $39.1(2.8)$ & $17.8(1.3)$ \\
\hline skp1 & N.D & 31.5 & 16.0 & 35.2 \\
\hline skp2 & 10.0 & $21.1(2.1)$ & $40.4(4.1)$ & $17.9(1.8)$ \\
\hline \multicolumn{5}{|l|}{$\mathrm{S}$} \\
\hline Cyclin C & 31.8 & $32.2(1.0)$ & $23.3(0.7)$ & $17.7(0.6)$ \\
\hline Cyclin G & 42.2 & $67.8(1.6)$ & 79.5 (1.9) & $72.7(1.7)$ \\
\hline Cyclin G2 & 16.6 & $15.2(0.9)$ & $27.6(1.7)$ & $17.5(1.1)$ \\
\hline CDC6 & 36.0 & $73.9(2.1)$ & $75.8(2.1)$ & $49.2(1.4)$ \\
\hline CDK7 & 17.1 & $58.2(3.4)$ & $77.0(4.5)$ & $81.2(4.7)$ \\
\hline MCM6 & 53.0 & $69.0(1.3)$ & $69.9(1.3)$ & $62.7(1.2)$ \\
\hline \multicolumn{5}{|l|}{$\mathrm{G}_{2}$} \\
\hline Cyclin B & 31.5 & $46.5(1.5)$ & 49.7 (1.6) & $40.2(1.3)$ \\
\hline Cyclin B2 & 130.6 & $114.4(0.9)$ & $111.2(0.9)$ & $110.1(0.8)$ \\
\hline \multicolumn{5}{|l|}{ M } \\
\hline cdk1 & 74.8 & $86.5(1.2)$ & $91.3(1.2)$ & $79.1(1.1)$ \\
\hline $\mathrm{Cdc} 27$ & 123.7 & $102.0(0.8)$ & $96.8(0.8)$ & $90.9(0.7)$ \\
\hline MAD2L1 & N.D & 14.4 & 11.1 & 3.9 \\
\hline PRC1 & 101.1 & $99.9(1.0)$ & $100.8(1.0)$ & $100.9(1.0)$ \\
\hline Rbx-1 & 12.6 & $36.0(2.9)$ & $15.8(1.3)$ & $5.7(0.5)$ \\
\hline \multirow{2}{*}{\multicolumn{5}{|c|}{$\begin{array}{l}\text { DNA damage } \\
\text { checkpoint and } \\
\text { ATM pathway }\end{array}$}} \\
\hline & & & & \\
\hline Apaf-1 & 97.9 & $102.6(1.1)$ & 105.1 & $99.3(1.0)$ \\
\hline ATM & 73.1 & $84.5(1.2)$ & $87.3(1.2)$ & 79.9 (1.1) \\
\hline chk1 & 18.9 & $58.8(3.1)$ & $61.4(3.3)$ & $40.3(2.1)$ \\
\hline MRE11A & N.D & 27.8 & 28.5 & 13.3 \\
\hline MRE11B & N.D & 19.3 & 48.2 & 26.7 \\
\hline nibrin & 30.0 & $54.5(1.8)$ & $71.4(2.4)$ & $27.2(0.9)$ \\
\hline $\operatorname{chk} 2$ & 108.7 & $98.8(0.9)$ & $101.4(0.9)$ & $92.7(0.9)$ \\
\hline UBE1 & 23.1 & $70.6(3.1)$ & $73.4(3.2)$ & $56.4(2.5)$ \\
\hline E6-AP & N.D & 23.2 & 14.8 & 11.7 \\
\hline SUMO-1 & N.D & 8.8 & 18.6 & 6.2 \\
\hline \multicolumn{5}{|l|}{ Control } \\
\hline GAPDH & 70.5 & $87.5(1.2)$ & $96.8(1.4)$ & $86.0(1.2)$ \\
\hline PPIA & 100.0 & $100.0(1.0)$ & $100.0(1.0)$ & $100.0(1.0)$ \\
\hline
\end{tabular}

This table shows the optical density of the spots in cDNA array. Median pixel intensity of each spot in cDNA array was calculated using ScanAlyze software, which is a program for DNA microarray imaging and extracts median pixel intensity from the image data of spots. The gene expression levels are shown as a percentage of the intensity compared with the corresponding internal control, PPIA. The ratio of gene expression between control cells and HDAC inhibitor-treated and/or pCMV-Cx43-transfected cells was assessed by the fold difference. 

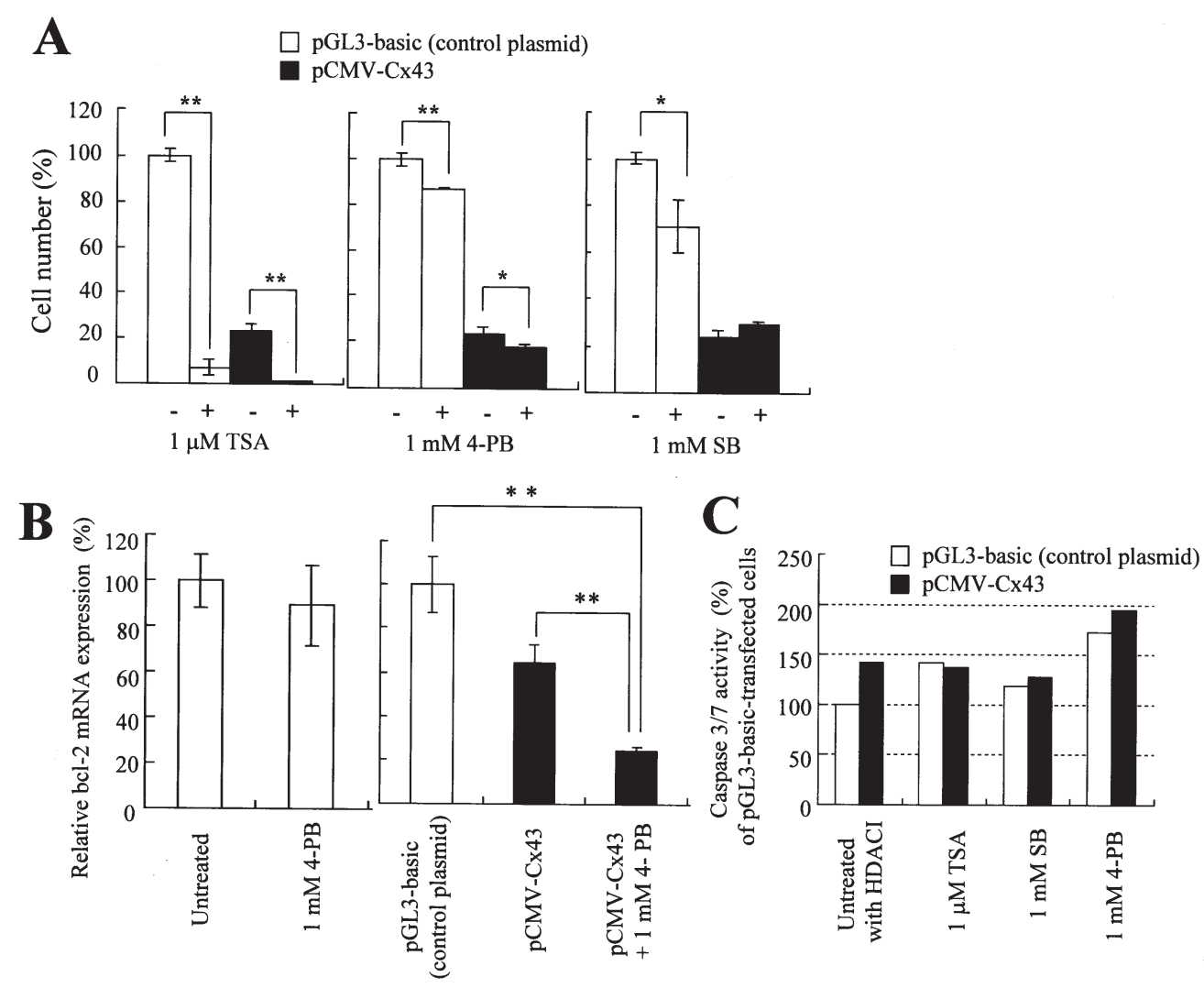

Figure 4. Effect of HDAC inhibitors on cytotoxicity in Cx43-transfected cells (A). KB cells were transfected with pCMV-Cx43 or pGL3-basic in the presence of $1 \mu \mathrm{M}$ TSA, $1 \mathrm{mM} \mathrm{SB}$ or $1 \mathrm{mM} 4-\mathrm{PB}$ and incubated for $48 \mathrm{~h}$. (B) Quantitative PCR analysis of bcl-2 mRNA expression in KB cells transfected with pCMV$\mathrm{Cx} 43$ and/or $1 \mathrm{mM}$ 4-PB. The y-axis indicates bcl-2 mRNA expression (\%) of untreated or pGL3-basic-transfected cells. The expression level of bcl-2 mRNA was normalized to the amount of $\beta$-actin in the same sample. Each result represents the mean $\pm S D(n=3)$. Statistical significance of the data was evaluated with Welch's t-test. ${ }^{* *} \mathrm{P}<0.01$, compared with pCMV-Cx43 plus 4-PB. (C) Effects of caspase-3/7 activities on Cx43-overexpressing KB cells by HDAC inhibitors. KB cells were transfected with pCMV-Cx43 or pGL3-basic in the presence of $1 \mu \mathrm{M} \mathrm{TSA}, 1 \mathrm{mM} \mathrm{SB}$ or $1 \mathrm{mM} 4-\mathrm{PB}$ and incubated for $24 \mathrm{~h}$. The results show caspase-3/7 activity as a percentage of the control (pGL3-basic-transfected cells). Each result represents the mean $(n=2)$.

in GJIC (22.2\%) (Fig. 2C), compared with the pGL3-basictransfected cells. Moreover, in the pCMV-Cx43-transfected cells, TSA, 4-PB and SB did not increase the GJIC $(24.2 \%$, $20.0 \%$ and $19.4 \%$, respectively) even though they induced the overexpression of $\mathrm{Cx} 43$ (Fig. 2D-F). These findings indicated that the transfection of $\mathrm{Cx} 43$ with an HDAC inhibitor could not increase the GJIC compared with Cx43 alone.

Next, to examine whether the $\mathrm{Cx} 43$ was transported properly to the plasma membrane and formed fluorescent puncta at cell-cell interfaces, we constructed a plasmid encoding a Cx43-EGFP chimera and investigated the localization of Cx43-EGFP protein in the cells. Confocal micrographs revealed that the Cx43-EGFP was localized to the intracellular compartment (Fig. 3A), suggesting that the defect of GJIC in the cells was due to an inability to assemble functional gap junctions. Furthermore, the transport of Cx43-EGFP was not affected by the co-introduction of TSA or 4-PB (Fig. 3B and C). In LNCaP cells, known to form assemblies of functional gap junctions at the membrane on transfection of the $\mathrm{Cx} 43$ gene (32). Cx43-EGFP showed the expected localization at sites of contact between the cells (Fig. 3D, arrow), suggesting that the subcellular targeting of Cx43-EGFP was not affected by the tagging with EGFP. From these results, KB cells could not correctly transport $\mathrm{Cx} 43$ protein into the membrane, therefore, the GJIC-mediated transfer shown in Fig. 2B might be regulated by another endogenous $\mathrm{Cx}$ species. Although functional gap junctions did not form in KB cells transfected with pCMV-Cx43, the expression of $\mathrm{Cx} 43$ could induce cell cycle arrest. There is evidence of gap junction-independent roles of $\mathrm{Cx}$ in the control of cell growth and the suppression of tumorigenicity (33). This finding suggests that the $\mathrm{Cx} 43$ expression in $\mathrm{KB}$ cells induced the cell growth inhibition via a GJIC-independent mechanism.

DNA array. To investigate the mechanism of growth inhibition by $\mathrm{Cx} 43$, we generated cDNA probes from KB cells transfected with pCMV-Cx43 or pGL3-basic in the presence or absence of TSA or 4-PB for $24 \mathrm{~h}$, and evaluated the effect on the expression of cell cycle-related genes which were among the key genes that affect progression through the cell cycle (Table I). PPIA and GAPDH were used as internal standards. In Cx43-transfected cells, compared with pGL3-basic-transfected cells, the expression of genes involved in the $G_{1}$ phase, DNA damage checkpoint, and ATM pathway, was up-regulated. An up-regulated mRNA expression was found in 11 genes in $\mathrm{G}_{1}$ phase (CDC7, cdk2, p16, Cks1p9, Cullin 2, Cullin 3, Cullin 4B, E2F-4, Nedd8, skp1 and skp2), 2 genes in S phase (CDC6 and CDK7), 2 genes in M phase (MAD2L1 and Rbx-1) and 6 genes involved in the DNA damage checkpoint and ATM pathway (chk1, MRE11A, MRE11B, UBE1, SUMO-1 and E6-AP) (Table I), with a difference of $\geq 2$-fold from pGL3-basic-transfected cells. The introduction of pCMV- 

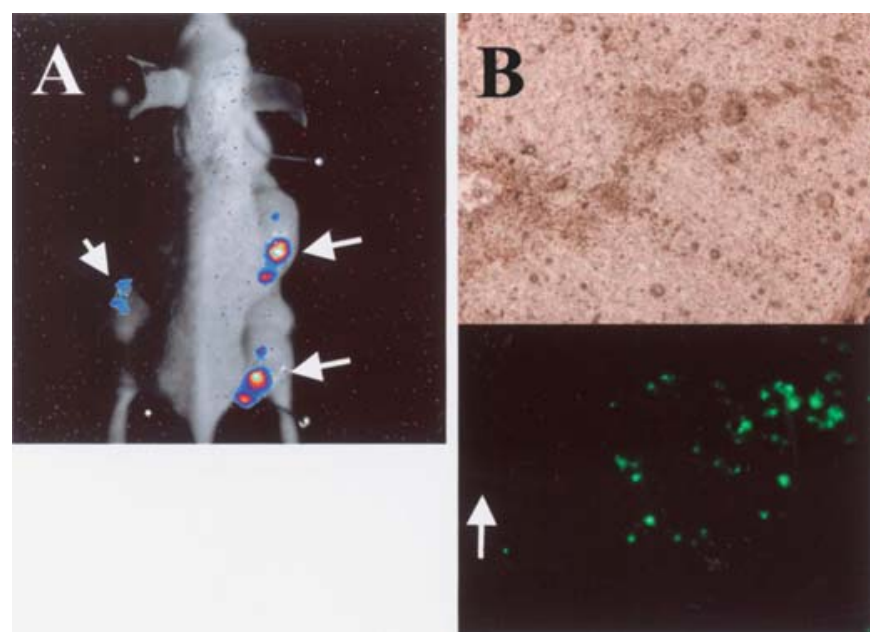

Figure 5. Tumor transfection in vivo. Xenografts of $\mathrm{KB}$ tumor cells were intratumorally injected with NP-F nanoplex of pCMV-luc (A) or pEGFP-C1 (B). (A) Twenty-four hours after intratumoral injections, mice were imaged and pseudocolor images representing light emitted from tumors superimposed over grayscale reference image of representative mice. (B) Photomicrographs of tumor after cryosection were taken with a $\mathrm{x} 40$ objective. Arrow, injection sites.

Cx43 plus 4-PB up-regulated mRNA expression in 2 genes in $\mathrm{G}_{1}$ phase (CDC7 and skp2), 2 genes in $\mathrm{S}$ phase (cyclin $\mathrm{G} 2$ and CDK7) and 3 genes involved in the DNA damage checkpoint (MRE11B, nibirin and SUMO-1) compared with that of pCMV-Cx43 alone. The introduction of pCMV-Cx43 plus TSA up-regulated mRNA expression in 1 gene in $\mathrm{G}_{1}$ phase (CDC7) and 1 gene in $\mathrm{S}$ phase (CDK7), compared with that of pCMV-Cx43 alone.

We also assessed the effect of pCMV-Cx43 on the cell cycle $24 \mathrm{~h}$ after transfection into KB cells (data not shown). Flow cytometric analysis revealed that transfection of pCMVCx43 caused an increase in the percentage of cells in $G_{1}$ phase (76\%) compared with transfection of pGL3-basic (70\%). Cotransfection with 4-PB or SB did not result in a substantial accumulation in $\mathrm{G}_{1}$ phase induced by $\mathrm{Cx} 43$ expression (77\%), but that with TSA caused a decrease in the percentage of cells in $\mathrm{G}_{1}$ phase $(58 \%)$.

Combined delivery of $p C M V-C x 43$ with HDAC inhibitors in vitro. HDAC inhibitors including TSA, 4-PB and SB have been used as antineoplastic agents (20). We investigated the cell viability $48 \mathrm{~h}$ after treatment with the HDAC inhibitor alone at optimal concentration for increased expression of $\mathrm{Cx} 43$ protein. As the result, $1 \mathrm{mM}$ TSA showed high cytotoxicity for the cells (7.3\% in cell viability), but $1 \mathrm{mM} 4-\mathrm{PB}$ and $1 \mathrm{mM}$ SB did not (71\% and $87 \%$ in cell viability, respectively) (Fig. 4A). Next, we explored whether the co-introduction of pCMV-Cx43 plus a HDAC inhibitor increased cytotoxicity. The co-introductions of pCMV-Cx43 plus TSA and 4-PB into the cells suppressed significantly tumor growth compared to that of pCMV-Cx43 alone, but pCMV-Cx43 plus SB did not (Fig. 4A). These results suggested that $1 \mathrm{mM} 4-\mathrm{PB}$ and $1 \mu \mathrm{M}$ TSA could induce a high level of $\mathrm{Cx} 43$ protein, and could increase suppression of cell growth by the co-introduction of pCMV-Cx43. However, to confirm suppression of tumor growth by overexpressed Cx43, co-introduction of pCMVCx43 plus 4-PB was adequate, because $1 \mu \mathrm{M}$ TSA exhibited strong cytotoxicity without $\mathrm{Cx} 43$ expression. Thereafter, we investigated the mechanism of inhibition of cell growth by the co-introduction of pCMV-Cx43 plus 4-PB and applied this combination to xenografts.

Effect of Cx43 with HDAC inhibitors on apoptosis in vitro. Tanaka and Grossman reported that overexpression of Cx26 in human bladder and prostate cancer enhanced the cytotoxicity of chemotherapy by down-regulating the expression of antiapoptotic bcl-2 $(15,16)$. Therefore, we examined the effect on the expression of bcl-2 mRNA $24 \mathrm{~h}$ after the transfection of Cx43 into KB cells by quantitative PCR analysis. pCMV-Cx43 transfection resulted in a down-regulation of bcl-2 mRNA expression compared with pGL3-basic transfection ( 64\%) (Fig. 4B). Furthermore, the transfection of pCMV-Cx43 plus 4-PB induced a significantly greater down-regulation ( $24 \%$ of pGL3-basic, respectively) of bcl-2 mRNA expression, whereas 4-PB alone did not.

Next, to examine the effect of $\mathrm{Cx} 43$ on the expression of apoptosis-associated enzymes, we measured caspase-3/7 activity $24 \mathrm{~h}$ after pCMV-Cx43-transfection with or without HDAC inhibitors (Fig. 4C). Caspase-3/7 activity in pCMVCx43-transfected cells was approximately 1.4-fold higher than that in pGL3-basic-transfected cells. The treatments with SB and TSA in pGL3-basic-transfected cells induced a 1.4and 1.2-fold increase in activity, respectively, compared with pGL3-basic alone, and the co-introduction of pCMV-Cx43 and SB or TSA did not increase the activity (1.4- and 1.3-fold that of levels in pGL3-basic-transfected cells, respectively). In contrast, the treatment with 4-PB in pGL3-basic-transfected cells induced the most potent caspase-3/7 activity (1.7-fold that of activity of pGL3-basic-transfected cells), and the cointroduction of pCMV-Cx43 and 4-PB enhanced the activity (1.9-fold that in pGL3-basic-transfected cells). These findings suggest that combining pCMV-Cx43 with 4-PB might result in an induction of caspase-3/7 activity in the cells.

In vivo transfection. To test the utility of NP-F for gene delivery in vivo, we evaluated transfection efficiency by intratumoral injection of NP-F nanoplex of pCMV-luc or pEGFP-C1 into $\mathrm{KB}$ tumor xenografts. NP-F induced luciferase expression at a high level around KB tumors (Fig. 5A), however, the distribution of EGFP-expressed cells was restricted to the center of the tumor mass in the vicinity of the injection site (Fig. 5B).

Combination gene therapy in KB tumor xenografts. To evaluate the potential for in vivo therapy in $\mathrm{KB}$ tumor xenografts, we evaluated the anti-tumor effect by directly injecting the NP-F nanoplex of pCMV-Cx43 or pGL3-basic following a direct injection of 4-PB once a day three times into the xenografts. Yamano et al reported that an intratumoral injection of HDAC inhibitor, FR901228, enhanced luciferase expression in solid tumors which were intratumorally injected with luciferase plasmid, whereas the intraperitoneal injection did not (21). Transfection with pCMV-Cx43 alone did not inhibit tumor growth compared with that by pGL3-basic (Fig. 6A). pGL3-basic plus 4-PB treatment moderately suppressed 

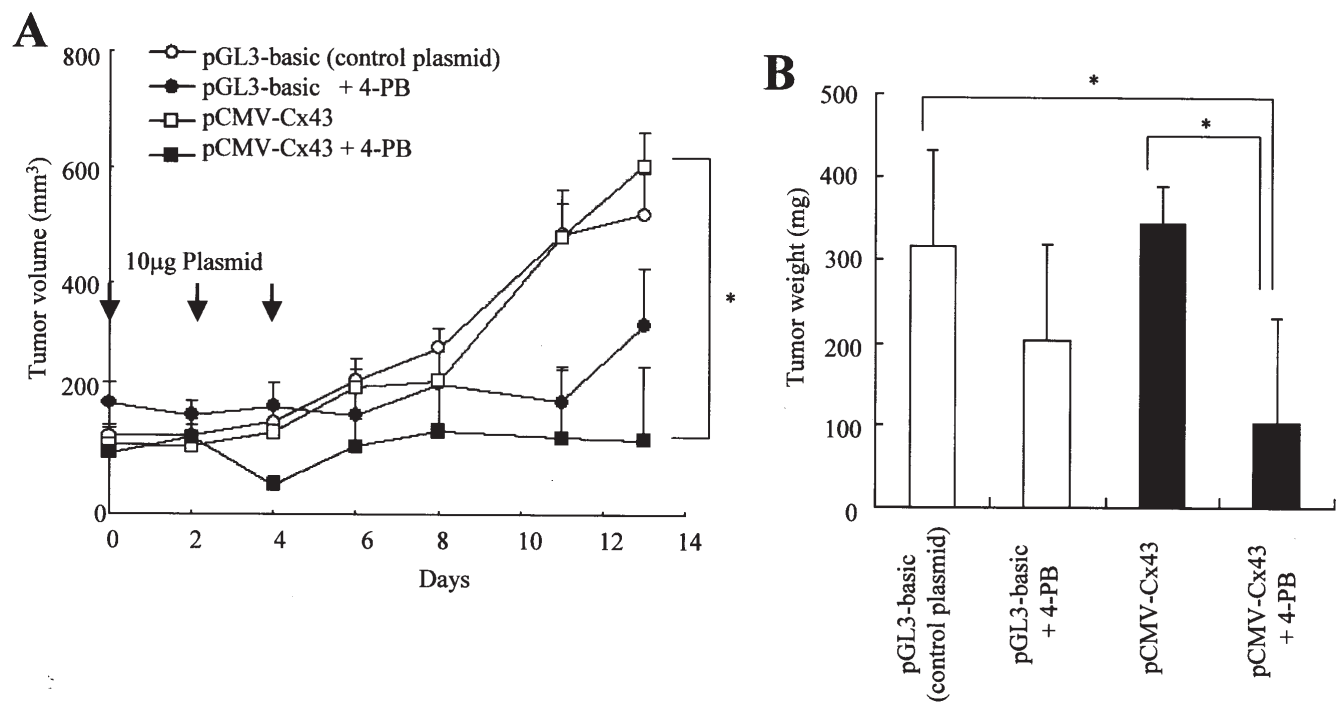

Figure 6. Tumor growth after intratumoral injection of pCMV-Cx43 plus 4-PB. An NP-F nanoplex of $10 \mu \mathrm{g}$ of pCMV-Cx43 or $10 \mu \mathrm{g}$ of pGL3-basic was injected on day 0,2 and 4 with or without $1 \mathrm{mg}$ of 4-PB as described in Materials and methods. Tumor volume was measured and the growth ratio was calculated as an increase in tumor volume (A). Tumor weight when all mice were sacrificed at day 13 (B). The results indicate the mean volume and weight \pm $\mathrm{SE}$ or SD, respectively $(\mathrm{n}=4)$. Statistical significance of the data was evaluated with Fisher's exact test. ${ }^{*} \mathrm{P}<0.05$, compared with the pCMV-Cx43 plus $4-\mathrm{PB}$.

tumor growth, but the effect was not statistically significant ( $\mathrm{P}>0.05)$. The introduction of pCMV-Cx43 plus 4-PB significantly suppressed tumor growth, and complete regression was observed in 2 of 4 tumors on day 13 after treatment. A comparison of tumor weight after excision also demonstrated that the tumor growth was significantly attenuated in the mice treated with pCMV-Cx43 plus 4-PB compared with just pGL3-basic (Fig. 6B). Neither the transfection of pCMV$\mathrm{Cx} 43$ alone, the injection of 4-PB alone, nor the introduction of pCMV-Cx43 plus 4-PB altered the change in body weight during 2 weeks of treatment (data not shown).

To determine the fate of tumor cells after gene therapy with pCMV-Cx43, KB tumor xenografts were analyzed by histological examination. The tumors treated with 4-PB showed no evidence of tumor cell death (Fig. 7B) even though the treatment suppressed tumor growth (Fig. 6A and B). Tumors transfected with pCMV-Cx43 exhibited many aggregated cells in the eosinophilic mass although transfection did not suppress tumor growth (Fig. 7C and E). The tumors transfected with pCMV-Cx43 plus 4-PB showed cell death in the eosinophilic mass (Fig. 7D and F). These findings suggested that the introduction of pCMV-Cx43 plus 4-PB had a strong anti-tumor effect on KB tumor xenografts.

\section{Discussion}

Restoring Cx expression and/or GJIC in Cx-deficient tumor cells by gene delivery may decrease tumor cell growth $(8,11)$. In the present study, we found that $\mathrm{Cx} 43$ expression induced significantly tumor growth inhibition in nasopharyngeal cancer $\mathrm{KB}$ cells via a GJIC-independent mechanism. Furthermore, enforced expression of $\mathrm{Cx} 43$ by 4-PB enhanced the cell death through activation of the apoptosis pathway, and the combined delivery of $\mathrm{Cx} 43$ with 4-PB suppressed the growth of tumor xenografts in vivo. This is the first report that enforced expression of $\mathrm{Cx} 43$ by 4 -PB has potential as a tumor growth inhibitor.
The transfection of pCMV-Cx43 into KB cells inhibited the cell growth (Fig. 1A), but $\mathrm{Cx} 43$ was localized to the intracellular compartment (Fig. 3A). Regarding the function of $\mathrm{Cx} 43$ in growth inhibition, a truncated $\mathrm{Cx} 43$ having the intracellular C-terminal domain of $\mathrm{Cx} 43$ could not form gap junctions but inhibited the tumor growth (12), indicating that $\mathrm{Cx} 43$ suppresses tumor growth via a GJIC-independent mechanism (33). The mechanistic aspects of the GJICindependent functions of Cxs remain largely unknown. Several possible mechanisms have been hypothesized (34). In Cx43-transfected cells, we found up-regulated mRNA expression in the $\mathrm{G}_{1}$ phase and DNA damage checkpoint and ATM pathway genes by cDNA array analysis (Table I). Cx43 transfection induced p16 expression, and the DNA-damageresponse by regulating the expression of Mre11A, Mre11B and nibrin, known to be important for mediating ATM-dependent checkpoint pathways (35). p16 is an important regulator of the cell cycle at the $\mathrm{G}_{1}$ phase (36). The expression of the nibrin and Mre11 genes was induced in an irradiation-evoked DNA damage checkpoint response $(37,38)$, suggesting that the transfection of pCMV-Cx43 had a similar or even identical underlying sensitivity to irradiation, and function in a similar signal pathway, in response to DNA damage. These findings corresponded with the result that $\mathrm{Cx} 43$-transfected cells had increased caspase-3/7 activity (Fig. 4C). Seul et al reported that the adenoviral delivery of $\mathrm{Cx} 37$ induced endothelial cell death through apoptosis (39). Overexpression of Cx43 in KB cells appears to regulate the expression of many genes involved in the $G_{1}$ phase of the cell cycle and apoptosis. This is the first report that $\mathrm{Cx} 43$ gene delivery induced effective growth inhibition via a GJIC-independent mechanism in $\mathrm{KB}$ cells.

Co-introduction of pCMV-Cx43 and TSA, SB or 4-PB into the cells up-regulated the expression of $\mathrm{Cx} 43$ protein (Fig. 1B). The amplification of $\mathrm{Cx} 43$ expression resulted from an increase in translation from Cx43 mRNA rather than in transcription from pCMV-Cx43. As another possibility, 

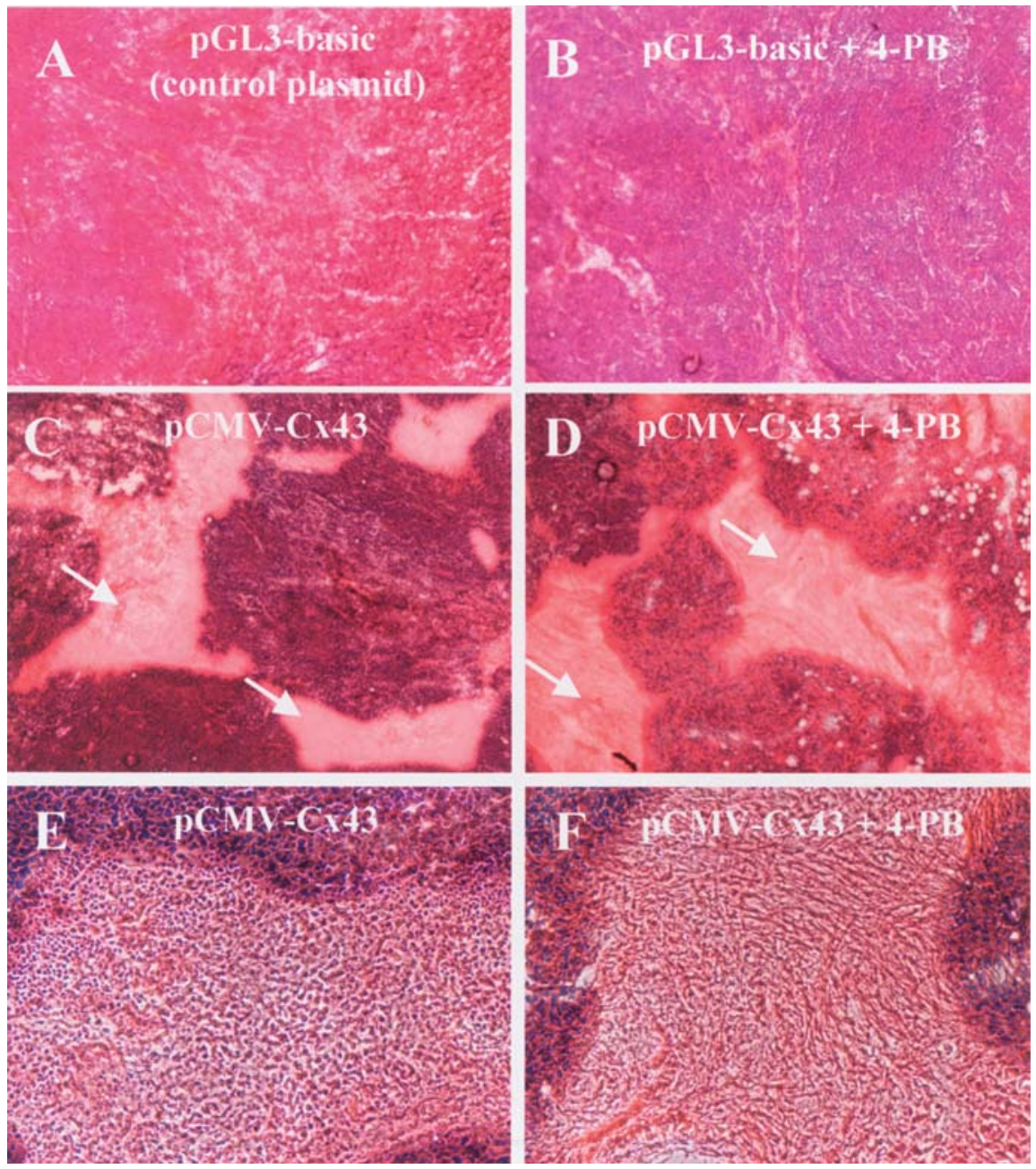

Figure 7. Histological analysis of tumors after Cx43 transfection and/or 4-PB treatment. Tumors were obtained when all mice were sacrificed at day 13. Photomicrographs of hematoxylin and eosin-stained sections of tumors were taken with x40 (A and D) and x100 (E and F) objectives. Tumor injected with $10 \mu \mathrm{g}$ of pGL3-basic (A), tumor injected with $10 \mu \mathrm{g}$ of pGL3-basic plus $1 \mathrm{mg} 4-\mathrm{PB}$ (B), tumor injected with $10 \mu \mathrm{g}$ of pCMV-Cx43 (C and E), and tumor injected with $10 \mu \mathrm{g}$ of pCMV-Cx43 plus $1 \mathrm{mg}$ 4-PB (D and F). Arrowheads: tumor death areas. (E and F) Magnifications of the area of tumor death observed as an eosinophilic mass in $\mathrm{C}$ and $\mathrm{D}$, respectively.

the amplified expression might result from an indirect effect on stabilization of $\mathrm{Cx} 43$ protein by HDAC inhibitors. Expression of endogenous $\mathrm{Cx} 43$ protein in $\mathrm{KB}$ cells was also weakly increased when the cells were treated with 4-PB or SB (Fig. 1B). Among the HDAC inhibitors, 4-PB up-regulated the expression of endogenous $\mathrm{Cx} 43$ in human gliomas $(40,41)$. Thus, pCMV-Cx43 plus either 4-PB or SB will be greater inducers for endogenous and exogenous $\mathrm{Cx} 43$ expression in nasopharyngeal tumors.

Combining pCMV-Cx43 with 4-PB or TSA in the cells enhanced the cytotoxicity, but that with SB did not (Fig. 4A). Several groups have reported that combining $\mathrm{Cx}$ gene therapy with a chemotherapeutic agent resulted in greater suppression of tumor growth $(14,15)$. Cx43 expression could enhance the sensitivity of human glioblastoma cells to doxorubicin, paclitaxel and etoposide (14). Transfection with the Cx26 gene induced down-regulation of bcl-2 expression in prostate cancer cells (15). Transfection of pCMV-Cx43 induced downregulation of bcl-2 expression in prostate cancer PC-3 cells, and increased sensitivity to docetaxel (42). In this study, the introduction of pCMV-Cx43 plus 4-PB in KB cells resulted in greater reduction of bcl-2 mRNA expression and induced caspase-3/7 activity (Fig. 4B and C). From the result obtained with the cDNA array, the co-introduction of 4-PB up-regulated mRNA expression in DNA damage checkpoint-related genes such as MRE11B, nibirin and SUMO-1 (Table I), suggesting an enhancement of the signal pathway in response to DNA damage. Furthermore, on the overexpression of $\mathrm{Cx} 43$ by 4-PB, strong expression of p16 protein was observed (Table I). Transfection of the p16 gene into nasopharyngeal carcinoma increased sensitivity to chemotherapeutic drugs such as $5 \mathrm{FU}$ and cisplatin (43). Therefore, the possible mechanism of enhanced efficacy with pCMV-Cx43 plus 4-PB might result from the effect of $\mathrm{Cx} 43$ overexpressed by $4-\mathrm{PB}$ to induce growth inhibition and the effect on increased cytotoxicity of 4-PB by down-regulating bcl-2 expression. This may provide valuable molecular therapeutic information to improve the clinical applications of both HDAC inhibitors and Cx43 gene therapy.

The introduction of pCMV-Cx43 plus TSA also resulted in significant reduction of tumor growth (Fig. 4A). However, from DNA array analysis, the introduction of pCMV-Cx43 plus 
TSA slightly affected mRNA expression of genes involved in DNA damage checkpoint and ATM pathway, compared with that of pCMV-Cx43 alone (Table I). These findings suggested that the mechanism of induction of apoptosis might be different between TSA and 4-PB. However, it was not clear why different responses to 4-PB and TSA in the induction of genes involved in the cell cycle, DNA damage checkpoint, and ATM pathway were observed.

In in vivo $\mathrm{Cx} 43$ gene therapy, $\mathrm{pCMV}-\mathrm{Cx} 43$ could not suppress the growth of KB tumor xenografts (Fig. 6A), but the tumors exhibited cell death (Fig. 7C and E). The observed restricted cell death in tumors may be due to the effect of Cx43 since the distribution of Cx expression by NP-F transfection into tumors was restricted to the center of the tumor mass in the vicinity of the injection site (Fig. 5B). Therefore, to induce inhibition of tumor growth by $\mathrm{Cx} 43$ expression alone, it is necessary to develop a gene carrier with the ability to introduce DNA widely into the tumor. 4-PB with pGL3basic suppressed tumor growth, but the tumors exhibited no evidence of cell death (Fig. 7B). HDAC inhibitors including 4-PB have been reported to inhibit the process of new capillary blood vessel formation or tumor angiogenesis, in addition to the inhibitory effect on cancer cell proliferation (44-46). The reduction in tumor size may be due to the antitumor effects of 4-PB. The combination of pCMV-Cx43 and 4-PB suppressed significantly tumor growth and weight in vivo compared with the control (Fig. 6), and resulted in massive tumor cell death (Fig. 7D and F), suggesting that the combined delivery showed a synergistic or additive effect in terms of growth inhibition and tumor toxicity. One explanation for enhanced growth inhibition by combination therapy might be that $\mathrm{Cx} 43$ increased sensitivity for 4-PB via the down-regulation of bcl-2. As another possibility, the reduction in tumor size by 4-PB may increase the transfection efficiency of $\mathrm{pCMV}-\mathrm{Cx} 43$, because significant tumor growth inhibition by intratumoral injection was obtained in tumor gene therapy when the tumor volume was $<50 \mathrm{~mm}^{3}$ (47). The combination of pCMV-Cx43 and an HDAC inhibitor transfected with NP-F has great potential as a tumor-targeted carrier for in vivo cancer gene therapy.

In conclusion, we demonstrated that $\mathrm{Cx} 43$ transfected by nanoparticle had a tumor suppressive effect via a mechanism that was independent of GJIC in $\mathrm{KB}$ cells, and combining pCMV-Cx43 with 4-PB resulted in significantly greater growth suppression of the cells and xenografts. Thus, the combination of Cx43 expression and an HDAC inhibitor may serve as a novel tool for gene therapy.

\section{Acknowledgements}

This project was supported in part by a grant from the Promotion and Mutual Aid Corporation for Private Schools of Japan, and by a Grant-in-Aid for Scientific Research from the Ministry of Education, Culture, Sports, Science, and Technology of Japan.

\section{References}

1. Vine AL and Bertram JS: Cancer chemoprevention by connexins. Cancer Metastasis Rev 21: 199-216, 2002.

2. Yamasaki H and Naus CC: Role of connexin genes in growth control. Carcinogenesis 17: 1199-1213, 1996.
3. Lee SW, Tomasetto C, Paul D, Keyomarsi K and Sager R: Transcriptional downregulation of gap-junction proteins blocks junctional communication in human mammary tumor cell lines. J Cell Biol 118: 1213-1221, 1992.

4. Tomasetto C, Neveu MJ, Daley J, Horan PK and Sager R: Specificity of gap junction communication among human mammary cells and connexin transfectants in culture. J Cell Biol 122: 157-167, 1993.

5. Habermann H, Ray V, Habermann W and Prins GS: Alterations in gap junction protein expression in human benign prostatic hyperplasia and prostate cancer. J Urol 167: 655-660, 2002.

6. Huang RP, Hossain MZ, Sehgal A and Boynton AL: Reduced connexin43 expression in high-grade human brain glioma cells. J Surg Oncol 70: 21-24, 1999.

7. Sawey MJ, Goldschmidt MH, Risek B, Gilula NB and Lo CW: Perturbation in connexin 43 and connexin 26 gap-junction expression in mouse skin hyperplasia and neoplasia. Mol Carcinog 17: 49-61, 1996.

8. Zhang ZQ, Zhang W, Wang NQ, Bani-Yaghoub M, Lin ZX and Naus CC: Suppression of tumorigenicity of human lung carcinoma cells after transfection with connexin43. Carcinogenesis 19: 1889-1894, 1998.

9. Oyamada Y, Oyamada M, Fusco A and Yamasaki H: Aberrant expression, function and localization of connexins in human esophageal carcinoma cell lines with different degrees of tumorigenicity. J Cancer Res Clin Oncol 120: 445-453, 1994.

10. Pelin K, Hirvonen A and Linnainmaa K: Expression of cell adhesion molecules and connexins in gap junctional intercellular communication deficient human mesothelioma tumour cell lines and communication competent primary mesothelial cells. Carcinogenesis 15: 2673-2675, 1994.

11. Mehta PP, Perez-Stable C, Nadji M, Mian M, Asotra K and Roos BA: Suppression of human prostate cancer cell growth by forced expression of connexin genes. Dev Genet 24: 91-110, 1999.

12. Zhang YW, Kaneda M and Morita I: The gap junctionindependent tumor-suppressing effect of connexin 43. J Biol Chem 278: 44852-44856, 2003.

13. Nicholas TW, Read SB, Burrows FJ and Kruse CA: Suicide gene therapy with Herpes simplex virus thymidine kinase and ganciclovir is enhanced with connexins to improve gap junctions and bystander effects. Histol Histopathol 18: 495-507, 2003.

14. Huang RP, Hossain MZ, Huang R, Gano J, Fan Y and Boynton AL: Connexin 43 (cx43) enhances chemotherapy-induced apoptosis in human glioblastoma cells. Int J Cancer 92: 130-138, 2001.

15. Tanaka $M$ and Grossman HB: Connexin 26 induces growth suppression, apoptosis and increased efficacy of doxorubicin in prostate cancer cells. Oncol Rep 11: 537-541, 2004.

16. Tanaka $M$ and Grossman HB: Connexin 26 gene therapy of human bladder cancer: induction of growth suppression, apoptosis, and synergy with Cisplatin. Hum Gene Ther 12: 2225-2236, 2001.

17. Peart MJ, Tainton KM, Ruefli AA, et al: Novel mechanisms of apoptosis induced by histone deacetylase inhibitors. Cancer Res 63: 4460-4471, 2003

18. Blagosklonny MV, Robey R, Sackett DL, et al: Histone deacetylase inhibitors all induce p 21 but differentially cause tubulin acetylation, mitotic arrest, and cytotoxicity. Mol Cancer Ther 1: 937-941, 2002.

19. Ishiguro K and Sartorelli AC: Activation of transiently transfected reporter genes in 3T3 Swiss cells by the inducers of differentiation/ apoptosis-dimethylsulfoxide, hexamethylene bisacetamide and trichostatin A. Eur J Biochem 271: 2379-2390, 2004.

20. Piekarz R and Bates S: A review of depsipeptide and other histone deacetylase inhibitors in clinical trials. Curr Pharm Des 10: 2289-2298, 2004.

21. Yamano T, Ura K, Morishita R, Nakajima H, Monden M and Kaneda Y: Amplification of transgene expression in vitro and in vivo using a novel inhibitor of histone deacetylase. Mol Ther 1: 574-580, 2000.

22. Imanishi R, Ohtsuru A, Iwamatsu M, et al: A histone deacetylase inhibitor enhances killing of undifferentiated thyroid carcinoma cells by p53 gene therapy. J Clin Endocrinol Metab 87: 4821-4824, 2002 .

23. Takimoto R, Kato J, Terui T, et al: Augmentation of antitumor effects of p53 gene therapy by combination with HDAC inhibitor. Cancer Biol Ther 4: 421-428, 2005.

24. Yamamoto S, Yamano T, Tanaka M, et al: A novel combination of suicide gene therapy and histone deacetylase inhibitor for treatment of malignant melanoma. Cancer Gene Ther 10: 179-186, 2003. 
25. Parker N, Turk MJ, Westrick E, Lewis JD, Low PS and Leamon CP: Folate receptor expression in carcinomas and normal tissues determined by a quantitative radioligand binding assay. Anal Biochem 338: 284-293, 2005.

26. Hattori Y and Maitani Y: Folate-linked lipid-based nanoparticle for targeted gene delivery. Curr Drug Delivery 2: 243-252, 2005.

27. Hattori Y, Kubo H, Higashiyama K and Maitani Y: Folatelinked nanoparticles formed with DNA complexes in sodium chloride solution enhance transfection efficiency. J Biomed Nanotech 1: 176-184, 2005.

28. Hattori Y and Maitani Y: Folate-linked nanoparticle-mediated suicide gene therapy in human prostate cancer and nasopharyngeal cancer with herpes simplex virus thymidine kinase. Cancer Gene Ther 12: 796-809, 2005 .

29. Robe PA, Jolois O, N'Guyen M, et al: Modulation of the HSVTK/ganciclovir bystander effect by n-butyrate in glioblastoma: correlation with gap-junction intercellular communication. Int J Oncol 25: 187-192, 2004.

30. Hattori Y and Maitani Y: Enhanced in vitro DNA transfection efficiency by novel folate-linked nanoparticles in human prostate cancer and oral cancer. J Control Release 97: 173-183, 2004.

31. Bartova E, Pachernik J, Harnicarova A, et al: Nuclear levels and patterns of histone $\mathrm{H} 3$ modification and HP1 proteins after inhibition of histone deacetylases. J Cell Sci 118: 5035-5046, 2005.

32. Govindarajan $\mathrm{R}$, Zhao $\mathrm{S}$, Song $\mathrm{XH}$, et al: Impaired trafficking of connexins in androgen-independent human prostate cancer cell lines and its mitigation by alpha-catenin. J Biol Chem 277: 50087-50097, 2002.

33. Jiang JX and Gu S: Gap junction- and hemichannel-independent actions of connexins. Biochim Biophys Acta 1711: 208-214, 2005

34. Zhang YW, Nakayama K, Nakayama K and Morita I: A novel route for connexin 43 to inhibit cell proliferation: negative regulation of S-phase kinase-associated protein (Skp 2). Cancer Res 63: 1623-1630, 2003.

35. Lee JH and Paull TT: ATM activation by DNA double-strand breaks through the Mre11-Rad50-Nbs1 complex. Science 308: 551-554, 2005.

36. Shapiro GI, Edwards CD and Rollins BJ: The physiology of p16(INK4A)-mediated G1 proliferative arrest. Cell Biochem Biophys 33: 189-197, 2000.
37. Desai-Mehta A, Cerosaletti KM and Concannon P: Distinct functional domains of nibrin mediate Mre11 binding, focus formation, and nuclear localization. Mol Cell Biol 21: 2184-2191, 2001

38. Gatei M, Young D, Cerosaletti KM, et al: ATM-dependent phosphorylation of nibrin in response to radiation exposure. Nat Genet 25: 115-119, 2000.

39. Seul KH, Kang KY, Lee KS, Kim SH and Beyer EC: Adenoviral delivery of human connexin37 induces endothelial cell death through apoptosis. Biochem Biophys Res Commun 319: 1144-1151, 2004

40. Asklund T, Appelskog IB, Ammerpohl O, Ekstrom TJ and Almqvist PM: Histone deacetylase inhibitor 4-phenylbutyrate modulates glial fibrillary acidic protein and connexin 43 expression, and enhances gap-junction communication, in human glioblastoma cells. Eur J Cancer 40: 1073-1081, 2004.

41. Ammerpohl O, Thormeyer D, Khan Z, et al: HDACi phenylbutyrate increases bystander killing of HSV-tk transfected glioma cells. Biochem Biophys Res Commun 324: 8-14, 2004.

42. Fukushima M, Hattori Y, Yoshizawa T and Maitani Y: Combination of non-viral connexin 43 gene therapy and docetaxel inhibits the growth of human prostate cancer in mice. Int J Oncol 30: 225-231, 2007.

43. Chow LS, Wang X, Kwong DL, Sham JS, Tsao SW and Nicholls JM: Effect of p16INK4a on chemosensitivity in nasopharyngeal carcinoma cells. Int J Oncol 17: 135-140, 2000.

44. Pili R, Kruszewski MP, Hager BW, Lantz J and Carducci MA: Combination of phenylbutyrate and 13-cis retinoic acid inhibits prostate tumor growth and angiogenesis. Cancer Res 61: 1477-1485, 2001.

45. Williams RJ: Trichostatin A, an inhibitor of histone deacetylase, inhibits hypoxia-induced angiogenesis. Expert Opin Investig Drugs 10: 1571-1573, 2001.

46. Kim MS, Kwon HJ, Lee YM, et al: Histone deacetylases induce angiogenesis by negative regulation of tumor suppressor genes. Nat Med 7: 437-443, 2001.

47. Galaup A, Opolon P, Bouquet C, et al: Combined effects of docetaxel and angiostatin gene therapy in prostate tumor model. Mol Ther 7: 731-740, 2003. 